\title{
Resource Isolating Mechanisms and Sustainable Competitive Advantage Among Commercial Banks in Kenya
}

\author{
Purity W. Ndegwa \\ Dr. James M. Kilika (PhD) \\ Dr. Stephen M. A. Muathe (PhD) \\ Department of Business Administration, \\ Kenyatta University, Nairobi, Kenya
}

Doi:10.19044/esj.2018.v14n34p38 URL:http://dx.doi.org/10.19044/esj.2018.v14n34p38

\begin{abstract}
Kenyan commercial banks are facing intense rivalry within the industry due to dynamic changes in the external environment. For survival in the industry, it is important that banks respond to the changes in the external environment. Sustainable competitive advantage has become the core focus of corporate strategy, has increasingly gained much attention in strategic management and is a concept which enables organizations to survive in the long-run. The main purpose of this study was to establish the effect of resource isolating mechanism on sustainable competitive advantage among commercial banks in Kenya. The specific objectives in this study were to ascertain the effect of economic deterrence, identification of rival competitive advantage and exploitation of opportunities on sustainable competitive advantage among commercial banks in Kenya. Descriptive and explanatory research designs were employed in the study. The research targeted all the commercial banks in Kenya. Purposive sampling was used to select a sample of 160 respondents from the key departments of Finance, Sales and Marketing, Strategy and Operations of all the forty (40) commercial banks' headquarters in Kenyan capital Nairobi. The data collection instrument used was semi-structured questionnaire. The variable characteristics were summarized using descriptive statistics. Agreement to the most frequent responses to the statements on the study variables ranged between moderate and high extent. Based on results of hypotheses testing, there exists a positive effect of resource isolating mechanism on sustainable competitive advantage.
\end{abstract}

Keywords: Resources, Isolating Mechanism, Competitive Advantage, Sustainable Competitive Advantage, Sustainability 


\subsection{INTRODUCTION}

Organization's success depends on its competitiveness in the industry. Therefore, organizations have put more focus on the area of strategic management for survival (He, 2012). Currently there is rapid change in economic and business environments, which has resulted to firms competing for profits, customers, and products that are perceived to be of value by customers and this has increased the rate of global competition among business entities (Dirisu, Iyiola \& Ibidunni, 2013). The firm's main concern is to defend its high market shares and reacting aggressively to the competitors moves by trying to build its own strengths (Porter, 1980).

Resource isolating mechanism is a crucial hypothetical concept which explains the competitive advantage sustainability process in a resource-based model for it discusses the competition among firms in a particular industry (Mahoney \& Pandian, 1992). An entity must be capable to discover rival competitive advantage, invest and earn superior performance, diagnose rival competitive advantage and acquire competitive resources and capabilities to remain competitive in a particular industry (Grant, 2010). The firm should also identify opportunities in the external environment, resource mobilization and employ skilled and experienced people to remain competitive (McGrath, 2013). When barriers to entry are high in an industry, competition declines over time and it makes it hard for beginning firms to get into the industry (Pearce \& Robinson, 2005).

A firm strategically positions its resources from its rivals and this is in four dimensions: competitive advantage of the firm, its financial strength, industry strength and stability of environment (Prasad, 2010; Cole \& Kelly, 2011; Johnson, 2011). According to Pearce and Robinson (2005); Thompson, Strickland and Gamble (2010) a firm is in a position to measure its competitiveness through comparing it with other entities in the same industry and that the firm's strength lies in the resources utilised, activities that the resources are engaged in and the extent to which they are rare, and immitable to competitors. Strategic plans that are able to tap internal strengths and responds to environmental opportunities, neutralizing micro threats and avoiding inner downfalls of the organization should be implemented in order to obtain sustainable competitive advantage (Oluwole, 2006).

Competitive advantage is created and sustained where a firm or an organization has the capacity or capability to defend its strategies against the competitive forces within the industry and also should have a competitive edge against rivals (Porter, 1985). Firm resources should have characteristics which are worthful, uncommon, matchless, non-substitutable and superior than rivals to create and sustain competitive advantage (Madhok, Li, \& Priem, 2010). Increased competition in the banking industry has led to reduced attractiveness and reduced profits among the industry players and as a result, the need for 
banks to aim at areas of competitive advantage so as to maintain a significant market presence (Kungu, Desta \& Ngui, 2014). Commercial banks should therefore, be able to exploit the competitive advantages in their resources to compete effectively in the market (Porter, 1985).

Commercial banks in Kenya should embrace technology for effective and efficiency service delivery and thus, enhance customer confidence and loyalty, improve service quality, minimize costs and maximize on profits (Mbobua, Juma \& Musiega, 2013; Kungu, Desta, \& Ngui, 2014). Processes and systems in operational activities should be developed effectively in order to maintain the structure of firm environment and as a result attain sustainable competitive advantage (Srivatsava, Franklin, \& Martinette, 2013). The resources central to competitive advantages should be recreated, reduplicated, redeployed or combined to bring growth (He, 2012).

The banking industry in Kenya has experienced increasing competition over the years whereby commercial banks have been competing among themselves and also with other financial institutions (Kungu, Desta \& Ngui, 2014). At the same time, the Central Bank of Kenya (CBK) Annual Report (2015) indicates that there has been high fluctuation in the level of competitive advantage achieved by individual banks in the last five years with several banks being ranked in different positions over the same period. The Banking Act chapter 488 requires banks to publish their results and bank charges which expose each bank to imitation by their rivals in the same industry (CBK, 2015). Most studies done in the banking sector in Kenya have laid emphasis on the strategies the banks need to adopt to gain competitive advantage (Kungu, Desta \& Ngui, 2014; Gudmundsson, Kisinguh \& Odongo, 2013). Studies done in strategic management focusing on competitive advantage have mainly focused on resources controlled by firms (Zekeri \& Nedelea, 2011; Ismail, Rose, Uli \& Abdullah, 2012; Chowtupili \& Rafi, 2013; Srivatsava, Franklin, \& Martinette, 2013; Mutunga, Minja \& Gachanja, 2014; Kungu, Desta \& Ngui, 2014; Auka, 2014).

The area of resource isolating mechanism has been given little attention in the banking industry and in strategic management. Hence, there is lack of adequate understanding on the set of resource isolating mechanism adopted by commercial banks in Kenya and how they influence sustainable competitive advantage in the banking industry, as well as the role played by capabilities generated by the bank resources and the external environment.

The purpose of this study therefore was to determine the effect of resource isolating mechanism on sustainable competitive advantage among commercial banks in Kenya. The specific objectives of the study were to determine the effect of economic deterrence on sustainable competitive advantage among commercial banks in Kenya, to determine the effect of identification of rival competitive advantages on sustainable competitive 
advantage among commercial banks in Kenya and establish the effect of exploitation of opportunities on sustainable competitive advantage among commercial banks in Kenya

The findings of this study are important to managers in various firms especially in the banking sector in Kenya and other developing countries through insight on which resource isolating mechanism should be embraced as a strategy for sustainability of their competitive advantage for survival in the industry. The research is of great importance to the government and organizational policy makers for they can use the findings in this research to formulate and develop strategies on resource isolating mechanism for implementation in both public and private sectors. This is because the research focused on the aspect of the barriers organizations should put in place to prevent competitors from imitating competitive advantages in their possession. The study provides insight on what resource isolating mechanism firms should embrace to sustain a competitive advantage. The study contributed towards filling of the information gap on the subject matter which is useful for future research. The study also contributed to the existing body of knowledge, which can be used as reference point by academicians, scholars and researchers.

\subsection{LITERATURE REVIEW}

This section reviews specific conceptual and empirical literature selected covering the main parameters used in this study aimed to point out current research gaps. It also emphasized on literature covered in other areas of resource isolating mechanism and sustainable competitive advantage and focused on identification of areas where research gaps exist. This section reviewed existing theories related to the study variables. Several theories have been advanced by scholars, researchers and writers in sustainable competitive advantage. The most prominent of these theories are resource-based theory, knowledge-based theory and institutional theory.

Resource Based Theory (RBV) provides a framework which explains and predicts the origin of the competitive advantage of the business (Konzlenkovan, Samaha, \& Palmatier, 2013). According to Grant, (1991), RBV approach helps the firm develop uncommon characteristics to realize the relationships that exist between firm resources, competencies, potentiality and its gainfulness and the mechanism that can be used to integrate these resources to sustain the competitive advantage. This can be achieved by designing and implementing strategies which can exploit the opportunities in the external environment (Grant, 1991). Resource based theory focused on firm resources and creation of sustainable competitive advantage (Barney, Ketchen, \& Wright, 2011). RBV explains how firms can compete effectively and efficiently by exploitation of specific resources and capabilities which 
possesses uniqueness and are immitable by competitors for they are factors of sustainable competitive advantage and high performance of the firm (Theriou, Aggelidis \& Theriou, 2009). Sustainability of competitive advantage is determined by the level to which competitors are able to match the uniqueness of their resources and that of other firms (Olavarrieta, \& Ellinger, 1997).

RBV identifies four characteristics known as resource isolating mechanism of firm's resources as physically unique (virtually impossible to imitate), path-dependent resources (very difficult to imitate), causal ambiguity (very difficult to imitate due to its complexity), economic deterrence (resources which requires high capital investment) (Pearce \& Robinson, 2005). Resource Based View theory is important in this study for its main concern is the resources controlled by a firm and how these resources can be linked to produce competitive advantage.

Knowledge Based-View (KBV) of an entity is a continuation of RBV (Grant, 1996; Curado, Lupi \& Lisboa, 2006). Knowledge-based resources include knowledge and intellectual abilities of employees, capacity to learn and expand on more knowledge, and have significant effect on the performance in the current business environment through sustainable competitive advantage (Jenkins \& Gupta, 1985). Knowledge-based view is an extension of resource based view of the firm in creation of competitive advantage, value and heterogeneity (Felin \& Hesterly, 2007). Creation and sustainability of competitive advantage depends upon inimitability of the capabilities and this underlies in the scope of specialized knowledge within an organization (Grant, 1996). The firm is able to create new value if its capabilities and knowledge are rooted in experts and specialist for this provides the starting point in creation and sustaining competitive advantage (Felin \& Hesterly, 2007).

Acquiring knowledge through learning triggers insights into organizational routines, beliefs, values and culture (Clegg, Kornberger \& Pitsis, 2014). Therefore, continuous learning of the organization's employees capable to develop capabilities and competencies that are sources of sustainable competitive advantage (Njuguna, 2009; Chowtupalli \& Rafi, 2013). The idea of knowledge rises into two distinct forms: explicit knowledge such as architects' drawings, business plans, patents, processes and techniques, tacit knowledge which includes experiences and background of the employees (Capon, 2009). KBV of an entity provides five very important characteristics which includes a Schumpeterian rent creation logic, it presents an important role in the sustainability of competitive advantage, it helps in development of idiosyncratic nonphysical assets through path reliability, it also increases knowledge and skills that cannot easily depreciate and causal ambiguity (Curado, Lupi \& Lisboa, 2006). Specialised knowledge enhances the firm's capabilities and competencies (Grant, 1996). Managers should 
therefore be able to identify staff with unique skills and talents which cannot be duplicated by rivals (Hatch, \& Dyer, 2004).

Institutional theory of organizations emerged from Philip Selznick and his students whereby they created an institutional theory model which viewed organizational structures as a means of shaping the organization's characteristics in response to the changes in the external environment (Tosi, 2009). Institutional theory of organizations provides a multifaceted view of firms and argues that firms are predisposed by normative pressures, from either internal or external sources (Zucker, 1987). Institutional theory is concerned with progressions by which structures are recognized as authoritative guidelines for social behavior (Scott, 2004).

Institutional theorists are concerned with how organizational structures and processes become established over time (Oliver, 1997). Institutional theory focuses mainly on distinguished and specialized cognitive and normative systems that classifies human activities within an organization (Tosi, 2009). Institutional theories see local actors (individuals, organizations or national states) as affected by institutions built up in much wider environments.

DiMaggio and Powell, (1983), identified three mechanisms of institutional isomorphic change: coercive isomorphism which arises from political influence and the problem of legitimacy; mimetic isomorphism which is as a result of standard responses to uncertainty and normative isomorphism which is associated with professionalism. The thought of institutional isomorphism is useful instrument for modern organizational dynamics (DiMaggio \& Powell, 1983). Rationalized institutions create myths of formal structure which shape organizations (Meyer \& Rowan, 1977). Therefore, institutional theory considers processes by which structures become established as authoritative guidelines for organizational behavior (Prasad, 2010). Therefore, institutional theory is important for it explains the firms structure which leads to institutional isomorphism (Zucker, 1996). Institutionalized organizations have the benefits of institutional strategies concerned with formation and development of institutions, rules and regulations controlling these structures. (Thomas, 1999).

Institutionalized institutions are capable of implementing decisions, adapt changes in the environment, able to construct internal structures in line with their goals and also manage workload in order to survive (Peters, 2000). Institutional resource isolating mechanism denotes barriers to imitation and this helps a firm to protect its competitive advantage (Oliver, 1997). Institutional Theory in this study is an important guide for it emphasis on structures that support processes of organization for sustainability of competitive advantage. Institutional theory in this study addresses the independent variables. 


\section{Conceptual and Empirical Review}

Strategic resources possess four characteristic attributes that provide a firm with the potential for sustainable competitive advantage: the resource must be valuable such that it exploits the opportunities and/or neutralizes threats in the firm's environment, it must be rare among rivals and industry of operation, the resource must be imitable for competitors and the resource must have no equivalent substitutes and hence unique (Dess, Lumpkin \& Eisner, 2011). Unique resource is the one which cannot be imitated by rivals, helps a firm to carry out some activities or functions better than competitors and this enables the firm to be distinguished for its excellent performance (Collis, 2013). Ensuring sustainable competitive advantage through product differentiation establishes brand reputation of a product and this attracts customer loyalty (Thompson, Strickland \& Gamble, 2010), this results in customer satisfaction and eventually helps the firm to retain its customers thereby creating entry barriers (Auka, 2014).

Effective supply chain management if managed helps the firm to sustain competitive advantage by creating better relationships with suppliers and customers and this is achieved by coordination, collaboration and integration of processes between the firm and its customers (Vinayan, Jayashree \& Marthandan, 2012). Differentiation strategy enables a firm to produce products customers perceive as different and valuable, and this is a basis for competitive advantage (Hoskisson, Hitt, Ireland \& Harrison, 2008; Grant, 2010). A skill and resource that foster differentiation include robust marketing abilities and market research abilities, product creation and innovation, creative talent, and corporate reputation for quality or technical leadership (Pearce \& Robinson, 2011).

Anyim (2012), studied on gaining sustainable competitive advantage through service differentiation among private hospitals in Nairobi. The purpose of the study was to determine service differentiation as a phenomenon among private hospitals in Nairobi in order to assess the extent to which service differentiation can be used to gain sustainable competitive advantage in the private hospital sector. The research used descriptive survey design. The target population was all private hospitals in Nairobi. A sample study of 30 private hospitals in Nairobi was selected through purposive sampling method. The study found that service differentiation strategy used by the private hospitals to gain competitive advantage enhances service delivery and leads to high customer loyalty. The recommendation from the study findings was that other sectors of the economy should practice service differentiation to gain competitive advantage. The study measured sustainable competitive advantage through service differentiation. However this study seeks a holistic view, that is, product differentiation being a determinant of sustainable competitive advantage. 
Kungu, Desta and Ngui (2014) found that equity bank used different competitive strategies among them the combination strategy, cost leadership strategy, differentiation strategy, and focus strategy and also it possessed various strengths that enabled it to survive in the market and also enabled it to compete favourably against rival firms. The study recommended that commercial banks should improve their information systems, come up with policies that would address the challenges they faced in maintenance of customer demands, pricing strategies and advanced technology to ensure improved quality and reduced costs to their customers. Kungu, Desta and Ngui (2014) also recommended further research in the area of the factors affecting the effectiveness of competitive strategies in dealing with falling demand of banking services in Kenya.

Economic deterrence as a form of resource isolating mechanism is a strategy that enable a firm to determine its internal strengths as a result of resources in its custody which enables effective exploitation of business opportunities and also development of a new generation of resources in order to sustain its competitive advantage (Chaharbaghi \& Lynch, 1999). Firms' should acquire, develop and build resources that create value to gain and sustain competitive advantage (Barney \& Hesterly, 2008). The study of sources of sustained competitive advantage focuses on valuable, rare, imperfectly, and non-substitutable resource controlled by a firm and tends to be harder for competitors to copy if they are based on unique bundles of resources (Barney, 2001; Dess, Lumpkin \& Eisner, 2009).

Firm's tend to rely more on intangible resources such as strong brand names, tacit knowledge and skills, organizational culture, company reputation, technical knowledge, unique business processes and partnerships for they are less invisible and more difficult for competitors to understand, purchase, imitate, or substitute in order to sustain competitive advantage (Hoskisson, Hitt, Ireland \& Harrison, 2010). Firms should therefore, identity, formulate and implement the relevant strategies whose benefits cannot be imitated by competitors to create and sustain competitive advantage (Bordella, Liu, Ravarini, Wu, \& Nigam, 2012).

The resources and capabilities of a firm contribute to creating and sustaining competitive advantage. Gaya, Struwig and Smith, (2013) found that the presence of tangible resources, both financial and capital are the main source of sustainable competitive advantage. The study was conducted in the motor vehicle industry in Kenya where senior managers and CEO were interviewed. The study concluded that a firm should possess bundle of resources which are rare, immobile, inimitable and unsubstitutable in order to perform at higher level than rivals.

Gudmundsson, Kisinguh and Odongo (2013), studied on the role of capital requirements on Bank competition and stability: the case study of the Kenyan 
banking industry. The purpose of the study was to examine the role of capital requirements on bank competition and stability in Kenya for a period 20002011. The target population was thirty six commercial banks. Return on equity was an indicator in measuring earnings and profitability of the banking sector. Bank competition was measured by lerner index and the Panza Ross $\mathrm{H}$ Statistics. The study found that there was evidence that capital has a linear effect on competition and that there was benefit of increasing capital requirements on competitiveness which are realized once consolidation of resources take place. The study also found that bank structure was an important factor on the effect on bank performance.

Ismail, Rose, Uli and Abdullah, (2012) study sought to establish the relationship between organizational resources, capabilities, systems and competitive advantage. The target population consisted of manufacturers listed in the 2008 Federation of Malaysian Manufacturers Directory. A crosssectional research design was employed where structured questionnaire was used to obtain responses from the manufacturers. A sample of one thousand manufacturers were randomly selected however, 127 respondents duly filled and returned the questionnaires for analysis (12.7\% response rate). The study found that there was positive effect of organizational resources, capabilities and systems on competitive advantage and recommended that organizations should consider having sound work systems that facilitate internal capabilities and resources to achieve competitive advantage, and that the organization's should improve their research and development (R\&D) and product promotion capabilities to attain and sustain competitive advantage.

Identification of rival competitive advantages is a strategy that enables the firm evaluate the sustainability of its competitive advantage by benchmarking their business against key competitors for it enables the firm to identify the best practices for this as another way to judge the competitive strength of the competitors' in order to determine how to perform business efficiently and effectively (Pearce \& Robinson, 2011), and entails establishing comparison of performance of various companies in terms of their value chain activities as well as costs of this activities (Thompson, Strickland \& Gamble, 2010).

Competitive factors that tend to increase rivalry are categorized into attributes about firms within an industry and attributes about a product or service or markets (Carpenter \& Sanders, 2009). The key factors to consider in order to identify rival advantages are relationships with suppliers or distributors, range of product line, product quality/attributes, price competitiveness, and general image economies of scale, market share, foreign affiliates, promotion capability, product awareness, geographical location, financial capability, employees skills, core competencies, innovation and competitive advantage of competitors (Katsioloudes, 2006). Firm's ability to evaluate its competitive positioning improves its opportunities of scheming 
ways which effectively exploit surrounding opportunities and enable forecasting of short term and long term goals and profit potentials more accurately (Pearce \& Robison, 2005). Competitive strength assessment measures firm's competitive strength and weakness and is a list of the industry's key success variables, the greater a firm's overall strength valuation, the more potent its overall fight versus rivals (Thompson, Strickland \& Gamble, 2010).

Iberg (2015) studied on creating competitive advantage in the premium market segment through a sustainability strategy. The purpose of the study was to outline successful tactics of incorporating sustainability strategy in the company's objectives to create competitive advantage in the premium market segment. The study was done on different industries among them the clothing, transportation, restaurants, cleaning products in University of Tennessee. The researcher used secondary data from various publications. The finding was that firms that invest in sustainability create strong comparatives advantages for their businesses in the $21^{\text {st }}$ century. Creating new markets segments for sustainable products allows a firm to have a first mover advantage and allows their customers to have alternative products. By innovations and improved sustainable products firms are able to capture market share above their competitors and improved brand equity, the firms can improve their customers' perception. The recommendation was that sustainability of the firm's competitive advantage and strategies is a requirement for long term business success and this is due to rise in consumer demands for valuable products, strained resources and uncertainty in the firm's environment.

Kungu, Desta and Ngui (2014) found that equity bank used different competitive strategies among them the combination strategy, cost leadership strategy, differentiation strategy, and focus strategy and also it possessed various strengths that enabled it to survive in the market and also enabled it to compete favourably against rival firms. The study recommended that commercial banks should improve their information systems, come up with policies that would address the challenges they faced in maintenance of customer demands, pricing strategies and advanced technology to ensure improved quality and reduced costs to their customers. They also recommended further research in the area of the factors affecting the effectiveness of competitive strategies in dealing with falling demand of banking services in Kenya.

Exploitation of opportunities as a form of resource isolating mechanism is required due to increased rate of global competition, and thus firms must be capable to determine what their ups and downs are and also competitive advantage they would wish to attain and sustain (Dirisu, Iyiola \& Ibidunni, 2013). Huge investment costs and high capital requirement act as barriers to entry especially if the venture is risky or unrecoverable and research 
is also costly (Dess, Lumpkin \& Eisner, 2009; Katsioloudes, 2006). For a firm to sustain competitive advantage, it should deter imitation by occupying existing and potential strategic advantage to reduce the range of investment opportunities open to the competitors (Grant, 2010). The firm should also establish the products or services those have potential of creating value to customers (Srivastava, Franklin, \& Martinette, 2013).

Jekaterina (2010) studied on the strategic positioning and sustainable competitive advantage in food industry. The purpose of the study was to examine the concepts of sustainable competitive advantage and strategic position in the food industry in Germany. Qualitative study was conducted on three beverage producers and cases were analysed based on the theoretical models. The conclusion of the study was that evaluation of the company's success and its strategies should be performed by combining different theories and models for companies are complex structures and their success depends on different elements, whether is sustainable competitive advantage or strategic position. From the findings, the study also concluded that there is more evidence that successful strategic positioning starts with developing products based on the company's existing strengths of the product and competitive advantage. The study recommended for future research which should focus on the compatibility and comparison of theories on positioning and brand building strategies.

Choi and Shepherd (2004) studied on Entrepreneurs' Decisions to exploit opportunities in US. The purpose of the study was to establish the entrepreneurs decisions to begin exploiting business opportunities from the resource-based view. Experimental research design was used. The target population were entrepreneurs involved in high-technology located in business incubators in US. Thirty seven business incubators were randomly selected from the US list of incubator members whereby two sixty seven entrepreneurs were contacted via telephone or emailed letters. The respondents were CEOs or presidents of the business.

Only sixty eight respondents completed the experiment a rate of $24 \%$. The study found that it was likely for entrepreneurs to exploit opportunities if more knowledge of customer demands are perceived for new products, technologies are fully developed and presence of managerial capability and strong stakeholder support. Recommended for future research in order to develop understanding of opportunity exploitation to complement recent works on opportunity discovery and recognition (Choi \& Shepherd, 2004).

\section{Conceptual Framework}

The conceptual framework on figure 1, illustrates the direction of the relationship between study variables: Resource isolating mechanism and sustainable competitive advantage 


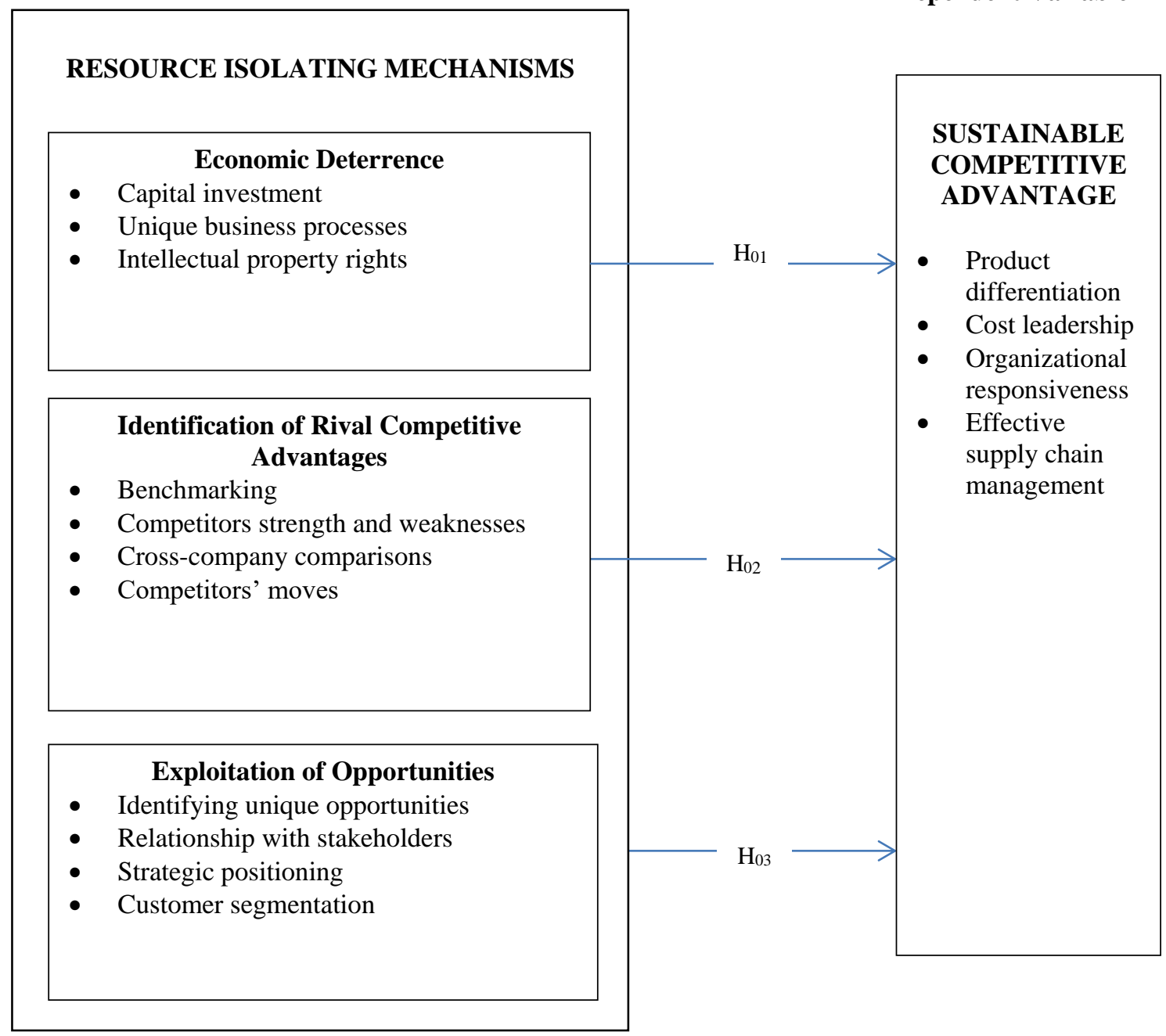

Figure 1: Conceptual Framework

Source: Author (2018)

\subsection{RESEARCH METHODOLOGY}

This study used both descriptive and explanatory research designs. As explained by Sekaran (2003), descriptive study helps to comprehensively describe the characteristics of the variables of interest in any situation. Explanatory research design further builds on the descriptive design and enables further discussion on causal effects of the variables under study. It is against this base that the researcher opted for a combination of descriptive and explanatory research design (Kothari, 2009). 
The population of this study was 40 commercial banks in Kenya. The targeted respondents were managers of key departments in these 40 commercial banks in Kenya. The study was conducted at the commercial banks' headquarters in Nairobi, Kenya. Consequently, the unit of analysis in this study was the bank while the unit of observation was the head of functional/departmental area. According to CBK (2015), commercial banks had been classified into three categories, which are tier one (large banks), tier two (medium banks) and tier three (small sized banks) according to the market share. The study applied purposeful sampling method, as a technique to select respondents from the four key departments of Finance, Sales \& Marketing, Operations and Strategy. In every bank four respondents were targeted.

Primary data was collected using self-administered semi-structured questionnaire. The questionnaire contained both open-ended and close-ended questions for ease of collecting quantitative and qualitative data. Open ended questions was used since gave respondents a chance to freely express their attitude and perception thereby providing qualitative insight to the study. The research instruments was validated in terms of content and face validity. Content validity provided adequate coverage of the investigative questions guiding the study for it contained a representative sample of the universe of the subject matter of interest (Cooper \& Schindler, 2003).

The closer Cronbach's alpha is to 1, the higher the internal consistency (Sekaran, 2003; Weiner \& Hopkins, 2007). The researcher measured the reliability of the questionnaire to determine its consistency. The test re-test technique was used to estimate the reliability of the instruments which involved administering the same test twice to the same group of respondents. As a rule of the thumb, reliability value of 0.7 and above is recommended for it showed reliability of the instrument (Robert, 2006). This study used a cut off coefficient point of 0.7 and above as a strong measure of coefficient. The overall score of reliability for the four variables was 0.867 which was greater than the adopted threshold of 0.7 as recommended by Robert (2006).

Quantitative methods, data analysis involved computation of both descriptive and inferential statistics using Statistical Package for Social Sciences (SPSS). Descriptive statistics analysis entailed calculation of means, variances, coefficients' of variation, correlation coefficients and regression models constants of the responses without giving detailed explanation of the values computed. Output of these procedures was presented through frequency distribution tables, graphs and charts. In inferential procedures, interpretations of values obtained from descriptive analysis. Inferential statistics therefore, provide deeper understanding of descriptive statistics.

The research hypothesis was tested at $95 \%$ level of confidence in order to provide for drawing of conclusions that if the p-value is less than $5 \%$, the 
null hypothesis was rejected and the alternative hypothesis was accepted. If pvalue was greater than $5 \%$, the null hypothesis was not rejected and the alternative hypothesis was rejected. Pearson's product movement correlation (r) was derived to show the nature and strength of the relationship. Coefficient of determination $\left(\mathrm{r}^{2}\right)$ was used to measure the amount of variations in the dependent variable explained by the relationship between variables.

\subsection{FINDINGS}

This chapter presents the study findings which include the bio-data of the study responses, the descriptive analysis and the inferential analysis of the study.

\begin{tabular}{|c|c|c|c|c|}
\hline \multirow[t]{2}{*}{ Biographic characteristics } & \multicolumn{3}{|c|}{ Bank type } & \multirow[t]{2}{*}{ Total } \\
\hline & Tier 1 banks & Tier 2 banks & Tier 3 banks & \\
\hline \multicolumn{5}{|l|}{ Gender } \\
\hline Male & 4 & 15 & 40 & 59 \\
\hline $\begin{array}{c}\text { Female } \\
\text { Total }\end{array}$ & $\begin{array}{c}6 \\
10\end{array}$ & $\begin{array}{l}29 \\
\mathbf{4 4}\end{array}$ & $\begin{array}{l}35 \\
\mathbf{7 5}\end{array}$ & $\begin{array}{c}70 \\
129\end{array}$ \\
\hline \multicolumn{5}{|l|}{ Years of work } \\
\hline $\begin{array}{l}\text { Less than one year } \\
\text { 1-2 years } \\
\text { 3-5 years } \\
\text { 6-10 years } \\
\text { Above } 10 \text { years } \\
\text { Total }\end{array}$ & $\begin{array}{c}0 \\
0 \\
5 \\
4 \\
1 \\
\mathbf{1 0}\end{array}$ & $\begin{array}{c}0 \\
10 \\
17 \\
17 \\
0 \\
\mathbf{4 4}\end{array}$ & $\begin{array}{c}1 \\
17 \\
37 \\
18 \\
2 \\
75\end{array}$ & $\begin{array}{c}1 \\
27 \\
59 \\
39 \\
3 \\
\mathbf{1 2 9}\end{array}$ \\
\hline \multicolumn{5}{|l|}{ Age } \\
\hline $\begin{array}{c}21-30 \text { years } \\
31-40 \text { years } \\
41-50 \text { years } \\
\text { Total } \\
\end{array}$ & $\begin{array}{c}3 \\
7 \\
0 \\
\mathbf{1 0} \\
\end{array}$ & $\begin{array}{c}26 \\
17 \\
1 \\
44\end{array}$ & $\begin{array}{c}43 \\
28 \\
4 \\
75 \\
\end{array}$ & $\begin{array}{c}72 \\
52 \\
5 \\
\mathbf{1 2 9} \\
\end{array}$ \\
\hline \multicolumn{5}{|l|}{ Education } \\
\hline $\begin{array}{c}\text { Diploma } \\
\text { Degree } \\
\text { Masters } \\
\text { Other (specify) } \\
\text { Total }\end{array}$ & $\begin{array}{c}0 \\
8 \\
2 \\
0 \\
\mathbf{1 0}\end{array}$ & $\begin{array}{c}2 \\
34 \\
7 \\
1 \\
44\end{array}$ & $\begin{array}{c}1 \\
64 \\
9 \\
1 \\
75\end{array}$ & $\begin{array}{c}3 \\
106 \\
18 \\
2 \\
\mathbf{1 2 9}\end{array}$ \\
\hline
\end{tabular}

Source: Survey data (2017)

The researcher administered 160 questionnaires among the Commercial Banks of interest. However, 129 dully filled questionnaires were collected from the respondents translating to a response rate of $80.63 \%$ 
From the findings, majority of the respondents had worked for the banks between three to five years. Therefore, the respondents were experienced, skilled, knowledgeable and also exposed in regard to the operations of the bank. They were therefore, able to give accurate information regarding the operations of the bank. Majority of the respondents' academic qualification was degree category implying that they were knowledgeable and skilled and therefore, were well placed to make sound decisions of the banks' operations. They were also able to understand the research questions since they were literate.

This section of the study discusses the characteristics of the variables through measures of central tendency and dispersion of the mean and standard deviation respectively.

Table 2: Variable characteristics

\begin{tabular}{|l|c|c|c|c|}
\hline Variable & $\begin{array}{c}\text { No of } \\
\text { Items }\end{array}$ & $\boldsymbol{\alpha}$ Score & Mean & $\begin{array}{c}\text { Standard } \\
\text { Deviation }\end{array}$ \\
\hline Economic deterrence & 129 & 0.856 & 3.91 & 0.81 \\
\hline Identification of rival competitive advantage & 129 & 0.888 & 3.97 & 0.80 \\
\hline Exploitation of opportunities & 129 & 0.841 & 4.21 & 0.70 \\
\hline$\quad$ Sustainable competitive advantage & 129 & 0.905 & 3.94 & 0.82 \\
\hline Overall score & & $\mathbf{0 . 8 7 3}$ & $\mathbf{4 . 0 1}$ & $\mathbf{0 . 7 8}$ \\
\hline
\end{tabular}

The first variable of the study was economic deterrence and was used in the study because of its focus on existing resources in exploiting business opportunities and sustaining competitive advantage. The aggregate mean for the variable of economic deterrence was 3.91 indicating that overall, the respondents largely agreed to the statements on economic deterrence. The aggregate standard deviation was 0.81 indicating that variation of responses by the respondents was not high.

The second variable of the study was identification of rival competitive advantages and was used in the study because of its linkage of company environment and sustainable competitive advantage. The variable was measured using five indicators. The responses on all the statements on identification of rival advantages had an aggregate mean of 3.97 indicating that the respondents generally agreed to the statements on identification of rival advantage. The aggregate standard deviation was 0.80 , showing a low variation on the respondents' responses.

The third variable of the study was exploitation of opportunities and was used in the study because of its focus on exploitation of market environment in sustaining competitive advantage. The variables were measured using five indicators. Overall, the variable Exploitation of Opportunities had an aggregate mean of 4.21 showing that the respondents largely agreed to the statements on exploitation opportunities. The aggregate 
standard deviation was 0.70 indicating a low variation on the respondents' responses.

The dependent variable, sustainable competitive advantage was used in the study because of the expected outcomes from the resource isolating mechanism strategies. The variables were measured using six indicators. The responses on the statements on sustainable competitive advantage had an aggregate mean of 3.94 indicating that the respondents generally agreed to the statements on sustainability. The aggregate standard deviation was 0.82 indicating a low variation on the respondents' responses.

The main objective of the research was to determine the effect of resource isolating mechanism on competitive advantage sustainability among commercial banks in Kenya.

Table 3: Regression analysis for the direct relationship between resource isolating mechanism and sustainable competitive advantage

\begin{tabular}{|c|c|c|c|c|c|c|c|}
\hline \multicolumn{8}{|c|}{ Model Summary } \\
\hline Model & $\mathbf{R}$ & R Square & \multicolumn{2}{|c|}{ Adjusted R Square } & $\begin{array}{l}\text { Std. Error of the } \\
\text { Estimate } \\
\end{array}$ & \multicolumn{2}{|c|}{ Durbin-Watson } \\
\hline 1 & $.778^{\mathrm{a}}$ & .605 & \multicolumn{2}{|c|}{.596} & .42069 & \multicolumn{2}{|c|}{1.972} \\
\hline \multicolumn{8}{|c|}{ ANOVA $^{a}$} \\
\hline \multicolumn{2}{|c|}{ Model } & Sum of Squar & \multicolumn{2}{|c|}{ Df } & Iean Square & $\bar{F}$ & Sig. \\
\hline \multirow{3}{*}{1} & Regression & 33.939 & \multicolumn{2}{|c|}{3} & 11.313 & 63.922 & $.000^{\mathrm{b}}$ \\
\hline & Residual & 22.122 & \multicolumn{2}{|c|}{125} & .177 & & \\
\hline & Total & 56.061 & \multicolumn{2}{|c|}{128} & & & \\
\hline \multicolumn{8}{|c|}{ coefficients } \\
\hline \multirow{2}{*}{\multicolumn{3}{|c|}{ Model }} & \multicolumn{2}{|c|}{$\begin{array}{c}\text { Unstandardized } \\
\text { Coefficients }\end{array}$} & $\begin{array}{c}\text { Standardized } \\
\text { Coefficients }\end{array}$ & d & Sig. \\
\hline & & & B & Std. Error & Beta & & \\
\hline \multirow{4}{*}{1} & (Cons & ant) & .402 & .270 & & 1.490 & .139 \\
\hline & Economic D & eterrence & -.001 & .091 & -.001 & -.016 & .987 \\
\hline & $\begin{array}{r}\text { Identificatio } \\
\text { Advan }\end{array}$ & $\begin{array}{l}\text { of Rival } \\
\text { ges }\end{array}$ & .442 & .091 & .442 & 4.869 & .000 \\
\hline & ploitation of & Ppportunities & .424 & .082 & .408 & 5.148 & .000 \\
\hline
\end{tabular}

Source: Survey data (2017)

The first hypothesis of the study sought to determine the effect of Economic Deterrence on sustainable competitive advantage of commercial banks in Kenya. The hypothesis was stated in the null form as:

\section{Ho1: Economic Deterrence has no significant effect on sustainable} competitive advantage among commercial banks in Kenya.

From the established regression equation from the findings reported in Table 3, economic deterrence had a negative coefficient $(\beta=-0.01)$ and a statistical importance of $p>0.05$. The coefficient indicated that with all the other variables constant, one-unit increase in economic deterrence would cause a 0.01units reduction in sustainable competitive advantage. This 
indicates a negative relationship between economic deterrence and sustainable competitive advantage. However, the relationship was non-significant. As a result $\mathrm{H}_{01}$ was supported and the study concluded that economic deterrence had a negative effect on competitive advantage sustainability which was not statistically significant.

The second hypothesis of the study sought to determine the effect of identification of rival competitive advantage on sustainable competitive advantage of commercial banks in Kenya. The hypothesis was stated in null form as:

Ho2: Identification of Rival Competitive Advantages has no significant effect on Sustainable Competitive Advantage among Commercial Banks in Kenya

From the established equation, identification of rival competitive advantage had a positive coefficient $(\beta=0.442)$ and a significance of $p=0.000$ which is less than the threshold of $\mathrm{p}<0.05$. The coefficient indicated that, with all variables remaining constant, one unit increase in rival competitive advantage would result to 0.442 unit increase in sustainable competitive advantage among commercial banks in Kenya. This indicates a positive relationship between identification of rival competitive advantage and sustainable competitive advantage. As a result the study rejected $\mathrm{H}_{02}$ and concluded that identification of rival competitive advantage had a positive effect on sustainable competitive advantage which is statistically significant.

The third hypothesis of the study sought to determine the effect of exploitation of opportunities on sustainable competitive advantage of commercial banks in Kenya. The hypothesis was stated in the null form as:

$\mathrm{H}_{03}$ : Exploitation of opportunities has no significant effect on sustainable competitive advantage among commercial banks in Kenya

Exploitation of opportunities had a positive coefficient and significance at $\beta=0.408 ; p=0.000$. The coefficient indicated that, with all the variables remaining constant, one unit increase in exploitation of opportunities would result to 0.408 unit increment in sustainable competitive advantage among commercial banks in Kenya. The findings of the study indicated a strong positive relationship between exploitation of opportunities and sustainable competitive advantage at $p=0.00 ; t=5.148$. As a result the study rejected the null hypothesis and concluded that exploitation of opportunities had a positive effect on sustainable competitive advantage which was statistically significant.

The findings on hypothesis one can be explained using several bases. The first base is the demographic features of the respondents who engaged in the research. The demographic data reported in table 4.1 showed that the composition of demographic characteristics of the study was majorly between 
21 and 30 years of age, where most of the respondents had acquired post graduate education. The level of experience for majority of the respondents was between 3 and 10 years which is considered to be favorable especially for workers at top level of management where strategic decisions such as economic deterrence takes place. Based on industry statistics, most respondents worked in tier three banks as compared to tier one banks.

The second dimension used to explain the result on hypothesis one is the descriptive results reported on economic deterrence. From the descriptive findings on economic deterrence, the study observed that most respondents agreed to the elements of economic deterrence to a moderate extent with Investment of resources on business processes, Employment of highly qualified and competent workers and adequate workforce in organization structure having high mean scores. This indicates that much effort on investments by the banks has focused more on human resource component of their economic assets.

The variable of Economic Deterrence is one that focuses on investment in physical assets, intellectual property rights, human resources and business processes. Investments by their nature involve huge financial outlays in the short term, yet the returns are expected in the medium and long-haul. The indicators for this variable with high scores were those focusing on human capital investment. Even though the scores were high for employment of qualified workforce and one that is unique to its organization structure, the relative contribution of these towards competitive advantage may not have been realized. This interpreted in terms of previous research in this industry by Ismail et al., (2012), Gaya et al., (2013) whereby development and improvement on $\mathrm{HRD}$, and possession of bundle of resources could enable the firm to create and competitive advantage sustainability against their rivals.

The third basis used to explain the findings on Hypothesis One, is the set of previous empirical findings. The empirical findings supported that dynamic competitive capabilities of firms are not limited to the economic part of an organization and that value creation to customers as well as integration of various organizations functions that is, both human and physical assets, was key to ensuring sustainable competitive advantage (Mutunga et al., 2014). Hockinsson et al., (2010) agree on firm tendency to invest and rely on intangible resources that are rare, invisible and difficult for competitors to comprehend. Similarly, the study Ismail et al., (2012) found out a positive relationship between organization resources, capabilities, systems and competitive advantage. However, the study scope was in Malaysian manufacturing industry and the population was larger than the current study, further, the study focused on competitive advantage strategies and effective resource utilization. 
The fourth basis is on theoretical literature. The resource based view identifies four main characteristics of organization resources that enhance competitive advantage that is valuable, rare, inimitable and complex. Pearce and Robinson (2005) pointed out that these characteristics are also similar for sustainable competitive advantage in terms of being physically unique, pathdependent, causally ambiguous and possess economic deterrence characteristics against competitors. The RBV Theory emphasizes on unique resources which cannot be imitated by rivals in order to create and sustain competitive advantage (Das et al., 2000; Grant, 1991; Barney et al., 2011). The current study found that the economic deterrence was not significant and had unfavourable effect on competitive advantage sustainability.

Based on the findings and explanations given on hypothesis one, the study makes an important contribution towards the effect of economic deterrence on sustainable competitive advantage, that integration of both physical and human assets are essential in the future competitive advantage of an organization. Previous studies such as Zekeri (2011); Zekeri et al., (2012) had identified specialized skills, capabilities and assets strategic human resource skills for competitive advantage, in addition, the current study incorporates human resource skills as a form of resource isolating mechanism.

Several bases may be used to explain the findings on $\mathrm{H}_{02}$. First, the demographic statistics as shown in Table 4.1, indicated that $78.2 \%$ of the respondents had level of experience of more than two years, indicating some level of competence in understanding the environment of the banking sector. It is observed that the respondents have adequate understanding of the industry, competitive behaviors and so capable of projecting into their likely strategic moves during competitor analysis process in their strategic management process. Secondly, the Industry characteristics showed that a large percentage of the respondents (70.5\%) had worked in banking for more than three years and were in either tier two banks or tier three banks as compared to $7.8 \%$ of employees who worked for tier one banks. The tier two and tier three banks have more competitive edge in identification of rival advantage as compared to tier one banks. The tier one banks and tier two banks have a wide scope of operations, branch networks and more diverse environments.

The third basis is on the descriptive findings. The role of this variable in building competitive advantage is that of identifying rival intent and behavior so as to be proactive against competition. Capturing of strategic signals by competitors, Cross company comparison and monitoring of strategic moves, scored highly. Even though benchmarking and identification of rival strength scored relatively lower means, they have a lot of potential in helping companies identify rival advantages. The fourth base is on theoretical literature, where the knowledge based theory was used to interpret the 
findings. The theory was used on the argument that identifying that rival competitive advantage is acquired through selection of highly conscientious individuals or teams to develop more collectivist values that facilitate knowledge transfer and utilization in reinventing the wheel. The study included human resources of 31 and above years age group, who form a large percentage in both tier one banks and tier three banks and could also indicate the increased number of employees with longer work experience in the medium and large sized in the banking industry.

The fifth dimension is based on past empirical findings where, the high scores were based on dimensions of permanence, mobility and traceability that are considered along Sustainable Competitive Advantage which enable a firm measure resilience toward competition, extent of transfer of resources between competing firms and ease of imitation by competitors respectively (Grant 1995). In addition, Hazen and Bryd (2012) pointed that logistics information technology innovation and combination of firm's resources enhances production of the firm against rivals. From the findings and explanations given on hypothesis two, the study makes an important contribution that, focus on benchmarking and monitoring of competitor activities are rival competitive advantages that affect sustainable competitive advantage. Also, previous studies such as (Gitonga et al.,) did not discuss how rival advantages related to sustainable competitive advantage as in the current study.

Several bases explain the findings on Hypothesis three, first, the respondent demographics. About $96.1 \%$ of the respondent were youthful and therefore in a position to counter day to day activities. Also, most had worked for less than five years which shows the ability of individual banks to acquire competent workforce for sustainable competitive advantage. Second, the industry characteristics show that $63.5 \%$ of the employees in commercial banks who had worked in banks for less than five years were either in tier one banks or tier two banks, indicating that larger banks had a broader opportunity in exploitation of opportunities as compared to small sized banks.

Secondly, the role of the exploitation of opportunities on competitive advantage is that of activities that enable firm discover opportunities in the environment. The descriptive findings as in table 4.6 show that commercial banks consider all the indicators on exploitation of opportunities where scanning of business environment; market segmentation of customer groups; building strong relationships with customers; product positioning by the bank and stakeholder participation ranked highly. This indicates that the banks have given attention to strategic practices that seek to exploit external opportunities as a way of enhancing linkages with the external environment and so obtain a strategic fit. As a result, the strategic fitness attained, the high descriptive scores support the positive influence of exploitation of opportunities as a 
resource isolating strategy on sustainable competitive advantage among commercial banks.

Third basis is that, Institutional theory provides a complex view of organizations and argues that organizations are influenced by normative pressures, arising from external sources or within the organization itself (Zucker, 1987). It considers the processes by which rules, norms and routines become established guidelines for social behavior. Further, it posits that organizations that exclude legitimate elements of environment lack acceptable legitimated accounts of their activities which creates a gap on prevailing cultural norms, political interest and therefore a firms innovativeness lacks strategic direction and focus. This explains the positive contribution of the indictors on exploitation of opportunities. The study identified that scanning of the environment, stakeholder participation and relationship building actually enhance sustainable competitive advantage of banks.

Based on previous studies such as, Jaketerina (2010); Iberg (2015); Chowtupalli and Raffi (2013) a positive relationship exists between competitive advantages, customer relationship, information technology resources, exploitation of opportunities and sustainable competitive advantage. Chowtupalli and Raffi (2013) study asserted that resource configuration and organization identity were sources of competitive advantage practices that resulted to organization learning, knowledge management and innovation which are indicators of sustainable competitive advantage where resource configuration and organization identity serve as opportunities for firm to be rare and unique both internally and externally. Jekaterina (2010) further noted that strategic positioning of firms that entailed new product development based on company existing strengths and competitive advantages led to sustainable competitive advantage, similarly the study found out that banks considered environmental scanning, product positioning and market segmentation as indicators of exploitation of opportunities.

In relation to the above discussion, the study makes the following contribution: exploitation of opportunities through stakeholders and external environment has positive impact on strategic direction of sustainable competitive advantage. While the previous studies such as Choi and Shepherd (2004) did not relate exploitation of opportunities to performance outcomes which had the ability to explain how it influences Sustainable Competitive Advantage, the current study expands on this variable by incorporating performance measure.

\subsection{CONCLUSION AND IMPLICATION}

The objective of the study was to determine the effect of resource isolating mechanism on sustainable competitive advantage among Kenyan commercial banks. Relying on the study findings, the study makes several 
conclusions. Findings on research objective one indicated that economic deterrence was not statistically significant and had a negative effect on sustainable competitive advantage. Economic deterrence therefore, may not be of great help to Commercial banks in Kenya in sustainability of competitive advantage.

Regarding the research finding on objective relating to identification of rival competitive advantage, it was found to be significant and had a positive relationship with sustainable competitive advantage. The study found that commercial banks in Kenya which were able to bench mark the competitors' best practice, which monitors the rivals' strategic moves and continuously performs cross company comparisons were able to produce quality and differentiated products which sustains competitive advantage.

In regard to objective three, the study found that exploitation of opportunities was significant and had effect on competitive advantage sustainability. The study found that Kenyan commercial banks which regularly scans the environment, able to segmentation the market and product positioning creates and sustains competitive advantage. The study also found that banks which rely on strategic fitness acquire competitive resources in their business environment and thus, were in a situation of gaining and achieving sustainable competitive advantage.

The study found a positive effect of resource isolating mechanism on sustainable competitive advantage. This study findings makes several recommendations. Firstly, top management characteristics and external environment were found to influence the sustainability of competitive advantage. Therefore, top management of commercial banks, specifically strategy department should formulate and implement strategies which are future oriented and flexible such that the changes in the external environment especially changes in technology are taken care of.

It is also crucial for strategic managers in Kenyan commercial banks to incorporate strategic aspects such as strategic fitness, alignments and Top Management Teams (TMT) to facilitate strategic effectiveness of the resources acquired. Secondly, the managers in finance, operations and marketing should work together as a team to ensure that the resources of the banks are well utilized for the success of the bank. The finance department managers should emphasis more on allocation of resources on the strategies such as benchmarking, cross company comparison and monitoring of competitors moves which helps the bank to identify the rivals' competitive advantage for these activities were found to bestow attainment of sustainable competitive advantage of the commercial banks.

Thirdly, Operations managers of commercial banks should introduce mechanisms which help them deal with changes in the external environment. The mechanisms should also assist the management in decision making in 
regard to production of quality and valuable products or services which were found to have positive effect on overall sustainability of competitive advantage.

\section{Recommendations for Future Research}

The study can be replicated at a regional level in Kenya so as to contrast any variations on the regional characteristics. Future researches should consider replication to other regions, especially developing countries to establish any adjustments on study variables.

\section{References:}

1. Anyim, M. A., (2012). Gaining Sustainable Competitive Advantage Through Service Differentiation Among Private Hospitals In Nairobi.

2. Auka, D. O., (2014). Porter's Generic Competitive Strategies and Customer Satisfaction in Commercial Banks in Kenya. Eurasian Business \& Marketing Research Journal 1(1)

3. Barney, J., (1991). Firm Resources and Sustainable Advantage. Journal of Management 17(1) 99-120

4. Barney, J. B., (2001). Resource-based theories of competitive advantage: A ten-year Retrospective on the resource-based view. Journal of Marketing, 83-89

5. Barney, J. B., \& Hesterly, W. S., (2008). Strategic Management and Competitive Advantage, Concepts and Cases. $2^{\text {nd }}$ Edition, New Jersey: Pearson Prentice-Hill.

6. Barney, J. B., (2007). Gaining and Sustaining Competitive Advantage. $3^{\text {rd }}$ Edition New Jersey: Pearson International Edition.

7. Barney, J. B., Ketchen, D. J., \& Wright, M., (2011). The Future of Resource - Based Theory: revitalization or Decline? Journal of Management 37(5).

8. Bordella, M. D., Liu, R., Ravarini, A., Wu, F. Y., \& Nigan A. (2012). Sustained Competitive Advantage Using Business Entities (SCUBE): A Practical Approach for Business Agility

9. Chaharbaghi, K., \& Lynch, R., (1999). Sustainble Competitive Advantage: Towards a Dynamic Resource-Based Strategy

10. Capon, C., (2009).Understanding Strategic Management. Prentice Hall www.pearsoned.co.uk/capon

11. Central Bank of Kenya, (2015). Bank Supervision Annual Report 2015.

12. Choi, Y. R., \& Shepherd, D. A., (2004). Entrepreneurs' Decisions to Exploit Business Opportunities. Journal of Management 2004(3) 377395 
13. Chowtupalli, M. Y. and Rafi, S. A., (2013). Achieving Sustainable Competitive Advantage through Resource Configuration and Organizational Identity: an Empirical Study, International Journal of Management (IJM), 4(3).

14. Clegg, S., Kornberger, M., \& Pitsis, T., (2012). Managing and Organizations. An Introduction to Theory and Practice, $3^{\text {rd }}$ Edition, London: SAGE Publications Ltd.

15. Cole, G. A., \& P. Kelly, (2011). Management Theory and Practice, $7^{\text {th }}$ Edition. UK: South-Western Cengage Learning.

16. Collis, D. J., (2013). Creating Value: Successful Business Strategies. 'an innovative,customer-led approach to strategy'

17. Cooper, D. R., \& Schindler, P. S., (2003). Business Research Methods, $8^{\text {th }}$ Edition. McGraw-Hill/Irwin.

18. Curado, C., Lupi, R.M., \& Lisboa, (2006). The Knowledge BasedView of the Firm: From Theoretical Origins to Future Implications, ISSN 0874-8470

19. Dess, G. G., Lumpkin, G. T., \& Eisner, A. B., (2009). Strategic Management, Text and Cases, fourth Edition, New York: McGrawHill/Irwin.

20. DiMaggio, P.J., \& Powell, W.W. (1983). The Iron Cage Revisited: Institutional Isomorphism and Collective Rationality in Organizational Fields. American Sociological Review, 48(2), 147-160.

21. Dirisu, J. I., Iyiola, O., \& Ibidunni, O. S., (2013). Product Differentiation: A Tool of Competitive Advantage and Optimal Organizational Performance (A Study Of Unilever Nigeria Plc).

22. Felin, T., \& Hesterly, W. S., (2007). The Knowledge-Based View, Vested Heterogeneity, and New Value Creation: Philosophical Considerations on the Locus of Knowledge. Academny of Management Review 32(1) 195-218

23. Gaya, H. J., Struwig, M., \& Smith, E., (2013). Creating a Sustainable Competitive Advantange at a High Performing Firm in Kenya. African Journal of Business Management, 7(21)

24. Gitonga, A. G., Kilika, J. M., \& Obere, E., (2016). Generation Y Talent Management Strategy and Competitive Advantage: Case of Commercial Banks in Kenya. Journal of Human Resource Management, 4(2): 10-18

25. Grant, R. M., (1991). The resource-based theory of competitive advantage: implications for strategy formulation, California Management Review 33 (3)

26. Grant, R. M., (1996). Toward a Knowledge-Based Theory of the Firm, Strategic Management Journal, 17, 109-122. 
27. Grant, R. M., (2010). Contemporary Strategy Analysis, Text and Cases, Seventh Edition. UK: John Wiley \& Sons Ltd. Publications.

28. Gundmundsson, R., Kisinguh, K. N., \& Ondongo, M. T., (2013). The Role of Capital Requirements and Stability: The Case of the Kenyan Banking Industry.

29. Hatch, N. W., \& Dyer, J. H., (2004). Human Capital and Learning as a source of Sustainable Competitive Advantage, Stategic Management Journal 25: 1155-1178

30. Hazen, B., \& Byrd, T., (2012). Toward Creating Competitive Advantage with Logistics Information Technology, International Journal of Physical, Distribution and Logistics Management, 42(1): 835.

31. He, N., (2012). How to Maintain Sustainable Competitive Advantages, Case Study on the Evolution of Organizational Strategic Management, International Journal of Business Administration, 3 (5), 2012

32. Hoskisson, R. E., Hitt, M. A., Ireland, R. D., \& Harrison, J. S., (2008). Competing for Advantage, $2^{\text {nd }}$ Edition. USA: Thomsom Higher Education.

33. Iberg, A. E., (2015). Creating Competitive Advantage in the Premium Market Segment through a Sustainability Strategy.

34. Ismail, A. I., Rose, R. C., Uli, J., \& Abdullah, H., (2012). The Relationship Between Organisational Resources, Capabilities, Systems and Competitive Advantage.

35. Jekaterina, B., (2010). Strategic Positioning and Sustainable Competitive Advantage in Food Industry

36. Johnson, G., Whittington, R., \& Scholes, K., (2011). Exploring Strategy, Text and Cases, Ninth Edition. England: Prentice Hall Financial Times.

37. Katsioloudes, M. I., (2006). Strategic Management, Global Cultural Perspectives for Profit and Non-Profit Organizations. UK: Elsevier Inc.

38. Konzlenkova, I. V., Samaha, S. A., \& Palmatier, R.W., (2013). Resource- Based Theory in Marketing. Journal of Academy of Marketing Science

39. Kothari, C. R., (2009). Research Methodology: Methods \& Techniques (Second Revised Edition), New Age International Publishers, New Delhi.

40. Kungu, G., Desta, I., \& Ngui, T., (2014). An Assessment of the Effectiveness of Competitive Strategiesby Commercial Banks. International Journal of Education and Research, Nairobi.

41. Madhok, A., Li, S., \& Priem, R. L., (2010). The Resource-Based View Revisted: Comparative Firm Advantage, Willingness-Based Isolating 
Mechanism and Competitive Advantage. European Management Review, 7(91-100)

42. Mahoney, J. T., \& Pandian, J. R., (1992). The Resource-Based View within the Conversation of Strategic Management.Strategic Management Journal, 13(5).

43. Mbobua, J. K., Juma, S., \& Musiega, D., (2013). Challenges of Implementing Agency Banking: A Survey of Selected Commercial Banks in Kakamega County. The International Journal of Engineering and Science (IJES), 2(9): 41-45.

44. McGrath, R. G., (2013). Transient Advantage, Sportlight on Strategy For Turbulent Times, Harvard Business Review, HBR.ORG.

45. Meyer, J. W. , \& Rowan, B., (1977). Institutionalized Organizations: Formal Structure as Myth and Ceremony. American Journal of Sociology, 83(2).

46. Mutunga, S.L., Minja, D., \& Gachanja, P. (2014). Resource Configurations on Sustainable Competitive Advantage of Food and Beverage Firms in Kenya: A Resource Based View of the Firm. European Journal of Business and Management, 6(24).

47. Njuguna J. (2009). Strategic Positioning For Sustainable Competitive Advantage: An Organizational Learning Approach. KCA Journal Of Business Management, 2(1).

48. Olavarrieta, S., \& Ellinger, A. E., (1997). Resource Based Theory \& Strategic Logistics Research, International Journal of Physical Distribution and Logistics Management 27(9/10).

49. Oliver, C., (1997). Sustainable Competitive Advantage: Combining Institutional and Resource-Based Views.Strategic Management Journal, 18:9, 697-71.

50. Oluwole.I., (2006). Sustainability of Competitive Advantage: A Must for Every Firm, College of Business and Social Studies (Marketing)

51. Pearce, J. A., \& Robinson, R. B., (2005). Strategic Management, Formulation, Implementation, and Control, Ninth Edition, New York: McGraw-Hill Inc.

52. Pearce, J. A., \& Robinson, R. B., (2011). Strategic Management, Formulation, Implementation, and Control, Twelfth Edition, New York: McGraw-Hill Inc.,

53. Peters, B. G., (2000). Istitutional Theory: Problems and Prospects, 4L01 Forbes Quadrangle,Pittsburgh, PA 15260

54. Porter, M.E., (1985). Competitive Strategy: Creating and Sustaining Superior Performance. New York, The free Press

55. Porter, M. E., (1980). Competitive Strategy: Techniques for Analysing Industries and Competitors, New York, Free Press 
56. Prasad, L. M., (2010). Strategic Management. Educational Publishers, New Delhi.

57. Scott, W. R., (1987). The Adolescence of Institutional Theory, 32(4).

58. Sekaran, U., (2003). Research Method for Business: A Skill Building Approach, $4^{\text {th }}$ Edition, John Wiley \& Sons.

59. Srivastava, R. K., Shervani, T.A., \& Fahey, L. (1998). Market-based Assets and Shareholder Value: A Framework for Analysis, Journal of Marketing, 62, January, 2-18.

60. Theriou, N. G., Ageglidis, V., \& Theriou, G. N., (2009). A Theoretical Framework Contrasting the Resource-Based Perspective and the Knowledge-Based View. European Research Studies XII (3)

61. Thomas, B. L., (1999). Institutional Strategy. Journal of Management, 25(2), 161-188

62. Thompson, A. A., Strickland, A. J., \& Gamble, J. E., (2010). Crafting and Executing Strategy, Text and Readings. McGraw-Hill.

63. Tosi, H. L., (2009). Theories of Organization. SAGE Publications, Inc.

64. Vinayan, G., Jayashree, S., \& Marthandan, G., (2012). Critical Success Factors of Sustainable Competitive Advantage: A Study in Malaysian Manufacturing Industries, International Journal of Business and Management, Vol. 7, No. 22, 2012

65. Weiner, J., \& Hopkins, J. (2007). Measurement: Reliability and Validity Measures.

66. Zekeri, J., \& Nedelea, A., (2011). Strategies for Achieving Competitive Advantage, 11(2)(14).

67. Zuker, L. G., (1987). Institutional Theories of Organization. Annual Review of Sociology 13(443-464). 